\title{
Operationalizing and Testing the Concept of a Physical Activity Desert
}

\author{
Russell R. Pate, Marsha Dowda, Ruth P. Saunders, Natalie Colabianchi, Morgan N. Clennin, \\ Kerry L. Cordan, Geena Militello, Agnes Bucko, Dwayne E. Porter, and Wm. Lynn Shirley
}

\begin{abstract}
Background: The prevalence of childhood obesity is higher in economically and socially deprived areas. Higher levels of physical activity reduce the risk of excessive weight gain in youth, and research has focused on environmental factors associated with children's physical activity, though the term "physical activity desert" has not come into wide use. Methods: This exploratory study operationalized the term "physical activity desert" and tested the hypothesis that children living in physical activity deserts would be less physically active than children who do not. A cross-sectional study design was applied with 992 fifth-grade students who had provided objectively measured physical activity data. Five of 12 possible elements of the built environment were selected as descriptors of physical activity deserts, including no commercial facilities, no parks, low play spaces, no cohesion, and the presence of incivilities. Results: Univariate and multivariate analyses showed that only the absence of parks was associated with less physical activity in children. Conclusion: Children living in a "no park" zone were less active than their counterparts who lived near a park. This study contributes preliminary conceptual and operational definitions of "physical activity desert." Future studies of physical activity deserts should be undertaken in larger and more diverse samples.
\end{abstract}

Keywords: built environment, children, parks, play spaces, community cohesion, incivilities

Childhood obesity rates have increased in the United States and other economically developed countries..$^{1,2}$ To better understand this trend, researchers have examined personal, family, institutional, community, and societal-level factors associated with greater risk for developing overweight and/or obesity in youth. ${ }^{3,4}$ This research has shown that the prevalence of childhood obesity is unevenly distributed across geographic areas, 5,6 with higher rates in economically and socially deprived areas. ${ }^{7-9}$ Furthermore, evidence indicates racial/ethnic and socioeconomic disparities in the extent to which adolescents' neighborhoods support physical activity ${ }^{10}$ and access to food stores, restaurants, and healthy foods. ${ }^{11}$

Because energy balance and the development of adiposity are influenced by diet and physical activity, ${ }^{12,13}$ there has been interest in determining whether or not patterns for these behaviors associate with geographic patterns for the prevalence of overweight/ obesity. ${ }^{14}$ Lack of access to food outlets that offer a full range of products, including fresh fruits and vegetables, is associated with high rates of overweight and obesity, ${ }^{15,16}$ giving rise to the term "food desert," in which there is "limited access to affordable and healthy food." 17 The prevalence of childhood obesity is greater in geographic areas characterized as food deserts, but there is limited evidence showing that residing in a food desert is associated with a greater prevalence of adverse dietary behaviors. ${ }^{18-23}$

\footnotetext{
Pate, Dowda, Clennin, Cordan, Militello, and Bucko are with the Deparment of Exercise Science, University of South Carolina, Columbia, SC, USA. Saunders is with the Department of Health Promotion, Education and Behavior, University of South Carolina, Columbia, SC, USA. Colabianchi is with the Department of Kinesiology, University of Michigan, Ann Arbor, MI, USA. Clennin is also with Kaiser Permanente, Institute of Health Research, Aurora, CO, USA. Porter is with the Department of Environmental Health Sciences, University of South Carolina, Columbia, SC, USA. Shirley is with the Department of Geography, University of South Carolina, Columbia, SC, USA. Pate (rpate@ sc.edu) is corresponding author.
}

Higher levels of physical activity are known to reduce the risk of excessive weight gain in youth, ${ }^{12,24,25}$ and research has focused on both geographic patterns and physical environmental factors, such as park availability, walkability, and safety, associated with children's physical activity behavior. ${ }^{26}$ Some studies have shown that supportive neighborhood features are associated with more physical activity, ${ }^{27}$ but others found no association. ${ }^{28}$ These mixed results may be due to a failure to consider a combination of environmental and psychosocial factors ${ }^{29}$ or to variability in definitions of supportive/nonsupportive environments. ${ }^{30}$ Despite this evidence, the term "physical activity desert" has not come into wide use. Cohen et al ${ }^{31}$ studied "play deserts" and reported that, in neighborhoods deemed food deserts, multiple parks existed but were underutilized.

The present study builds on the work of Cohen et al, ${ }^{31}$ as well as previous research on physical environmental influences on children's physical activity, ${ }^{26}$ and tested the hypothesis that children who live in physical activity deserts would be less physically active than children who did not live in those areas. The specific purposes of this exploratory study were (1) to operationalize the concept of the physical activity desert using information available in a data set that included extensive information on the built environment and (2) to determine whether or not objectively measured physical activity differed between children residing in physical activity deserts and those living in more physical activityresource-rich geographic areas.

\section{Methods}

\section{Conceptual Definition of Physical Activity Desert}

The initial step in the process of operationalizing and evaluating the concept of the "physical activity desert" was to define this term. A literature search failed to identify a definition of the term "physical activity desert." Therefore, drawing on definitions of related 
concepts, we adopted the following conceptual definition: A physical activity desert is an area characterized by poor access to elements of the built environment that support or enable participation in physical activity. This definition guided the study design and methods. The home address of participating children was the focal geographic point for examining opportunities in the physical environment.

\section{Study Design, Participants, and Settings}

The analyses used data from the Transitions and Activity Changes in Kids study. As previously reported, ${ }^{32}$ this study measured children's physical activity levels objectively and examined multiple associated factors. Participant recruitment took place in 21 public schools from 2 South Carolina school districts. Parental consent and child assent were obtained prior to the data collection. Self-report measures, including demographics, were collected from the participants via a survey administered by laptop computer. The participants wore accelerometers, and the parents/guardians completed paper surveys, both of which were returned by the participants approximately 1 week later. Administrators and physical education (PE) teachers completed surveys pertaining to the school physical activity environment. Trained research staff collected observational data on physical activity resources and other physical environment features at the community, neighborhood, and street levels. The University of South Carolina's Institutional Review Board approved all data collection protocols.

The cross-sectional study design presented in this paper utilized baseline observations collected in 2010 from 992 fifth-grade students who had accelerometer data (456 boys and 536 girls). Students missing data for sociodemographic variables $(n=30)$ or environmental variables $(n=97)$ were eliminated, resulting in a sample of 865 fifth-grade students (45.4\% male) with a mean age of 10.6 $(0.5)$ years. There were no race or gender differences between those who were included in the analysis and those excluded. However, parent education differed between the 2 groups, with a lower percentage of parents with more than a high school education in the group excluded from the analysis.

\section{Measurement of Physical Activity}

Physical activity was measured using ActiGraph GT1M and GT3X accelerometers (Fort Walton Beach, FL), which were attached to adjustable elastic belts. The data collectors instructed the participants to wear the accelerometer during waking hours for 7 consecutive days, removing the monitors only when bathing or swimming. Initialization of the accelerometers was completed prior to the data collection. The data collection began at 5:00 AM on the day following the monitor distribution. The data were collected in 1-minute epochs, and nonwear time was defined as any period of 60 or more minutes of consecutive zero counts. Nonwear time was excluded from the analyses.

The data for Sundays were excluded from the analyses because of shorter wear time and lower compliance on those days. The children had to provide at least 2 days of 8 or more hours of data for each day to be included, and missing values were estimated by multiple imputation on the accelerometer data using Proc MI in SAS (version 9.3; SAS Institute, Cary, NC). We focused on total physical activity (TPA) because we were interested in identifying characteristics of the built environment that were associated with children's overall time spent in physical activity, not only physical activity performed at moderate to vigorous intensity. Accelerometer cut points $\geq 100$ counts per minute were used to determine the time spent in TPA. TPA was expressed as the mean daily minutes per hour of wear time. TPA was also calculated for out-of-school time, including after school (after 3:00 PM on weekdays) and all day on Saturday (ASPA).

\section{Measurement of Physical Environmental Variables}

The data sources in the Transitions and Activity Changes in Kids data set that were considered preliminary candidates for operationalizing the measure of a physical activity desert included (1) databases identifying physical activity resources (ie, parks, commercial facilities) and their locations in the 2 counties where the participants lived; (2) windshield surveys, which assessed street segment physical incivilities, lack of cohesion, and play and social space; (3) school administrator/physical education teacher surveys, which measured the presence of school indoor and outdoor facilities and open community access to school facilities; (4) parent survey items, which quantified the presence of physical activity equipment in and around the home; and (5) GIS zoning and land use databases, which identified industrial areas. All buffer analyses were conducted using planar, straight-line distances. As described below, 12 variables were considered for operationalizing a physical activity desert.

Identification of Numbers and Locations of Physical Activity Facilities. The places that children might be active were identified from a variety of sources (ie, internet resources and databases) and included addresses of commercial facilities and parks in the 2 counties. Trained data collectors visited the identified places and geocoded the location. The number of parks in a 0.75 -mile buffer around a child's home address was created with GIS software (ArcGIS, version 10.1; Esri, Redland, CA). Similarly, a 2-mile buffer around each child's home was used to create a count for commercial facilities. For analysis, the presence of commercial facilities was dichotomized into none versus one or more in the buffer area and coded such that not having commercial facilities, which reflects a characteristic of a physical activity desert, was coded as 1 . The presence of parks was coded in the same manner.

Windshield Survey. A windshield survey (Neighborhood Attributes Inventory $)^{33}$ of the street segment around the immediate area of each child's home was completed by trained research staff during the summer after the child's fifth-grade year. A street segment was defined as the street area between 2 consecutive cross streets; it included both sides of the street, and the total length did not exceed 0.5 miles. As previously described, ${ }^{29} 3$ scales were summarized from the windshield data, based on the protocol for the Neighborhood Attributes Inventory, and included rating scales reflecting physical incivilities (ie, vacant residences and commercial buildings, poor ground conditions, litter, graffiti, and poor condition of public spaces), no cohesion (ie, crime watch signs, residents' reaction to raters, one-third or more homes with borders/ hedges, one-third or more homes with security bars, one-third or more homes with decorations, and signs denoting neighborhood name), and play and social space (ie, social norms as indicated by the presence of people, children visibly playing, one-third or more homes with yards, one-third or more homes with porches, nonresident visitors, such as service workers, the presence of parks, parks in good condition, street was not a busy thoroughfare, and the presence of sidewalks).

The 3 scales were dichotomized for this study such that values reflecting characteristics of a physical activity desert were coded as 1 . Thus, the incivilities scale reflected a physical activity desert if one or more incivilities were observed. The no-cohesion scale 
reflected a physical activity desert when no attributes were observed. The play and social spaces scale reflected a physical activity desert when 2 or fewer attributes were observed (ie, low play spaces). Interobserver reliabilities for the windshield for incivilities, no cohesion, and social spaces were $>0.80$.

School Surveys: Physical Education Teacher and School Administrator. The number of indoor and outdoor physical activity resources on school grounds was reported by the lead physical education teacher at each participating school, based on items from the School Health Policies and Programs Study. ${ }^{34}$ Teachers marked "yes" or "no" for the presence of 8 indoor and 9 outdoor resources. Also based on School Health Policies and Programs Study, school administrators reported whether physical activity facilities were available for use by children or adults for any community-sponsored sports, classes/lessons, or open/free-play programs, as well as open-use by children and adults during nonschool hours for noncommunity-sponsored programs or free-play (coding yes/no for 6 categories: child free play, child sports, child community programs, adult free use, adult sports, and adult community programs)..$^{34}$

Parent Survey. Physical activity equipment in the home was reported via a checklist completed by a parent/guardian as part of a parent survey completed during the period when the participating child was wearing the activity monitor. The parents reported the presence (yes/no) of 14 items/spaces that children could use to be active in and around the home (range 0-14). ${ }^{32}$

Land Use and Zoning Codes. Land use and zoning code data sets, obtained from local and county governments in both study areas, were used to define industrial areas. Using GIS, any portion of a 0.75-mile buffer around a child's home address that fell within an area zoned for industrial use as defined by city and/or county zoning laws was identified. If any proportion of the 0.75 -mile buffer around a child's home was zoned for industrial use, land use was coded as $1 ; 0=$ none of the buffer in an industrial zone.

\section{Statistical Analysis}

Descriptive analyses by demographic category were performed for the TPA sample $(n=865)$ and the ASPA sample $(n=746)$. The sample was smaller for afterschool and Saturday physical activity due to less compliance for accelerometer wear during those periods. The 2 physical activity samples were also examined by youth characteristics using $t$ tests or chi-square analyses to assess possible differences by demographic group.

To address the first study purpose, which was to operationalize the concept of the "physical activity desert" using information available in the data set, the research team conducted a series of meetings to consider and select potential variables from the 5 data sets for consideration as indicators of a physical activity desert; a subset of the variables was subsequently chosen to operationalize "physical activity desert." For each variable chosen to reflect a physical activity desert, we examined variable distributions and classified each participant as to whether they resided in a desert versus nondesert area for that feature. To address the second study purpose, we examined the relationship between each physical activity desert variable and physical activity using univariate analyses. Specifically, we used $t$ tests to compare the mean minutes per hour of TPA and ASPA for the participants residing in desert versus nondesert areas in an unadjusted analysis.

To further investigate individual items within the physical activity desert index, a stepwise regression analysis was run for
TPA and for ASPA using a $.99 P$ value for the level of entry. A linear regression was also run in which the 5 physical activity desert variables were entered into 2 models, one for TPA and one for ASPA, adjusting for gender, race, and parent education.

\section{Results}

\section{Sample and Youth Characteristics}

Table 1 presents the demographic and descriptive information on the study participants. The TPA and ASPA samples were very similar. A total of $45 \%$ of the sample were males, about $35 \%$ black, $10 \%$ Hispanic, $37 \%$ white, and $10 \%$ other race/ethnic groups. Approximately $58 \%$ of the youth had a parent with greater than a high school education.

Table 2 presents the physical activity by youth characteristics. Boys compared with girls had higher TPA and ASPA (29.3 [4.5] vs 27.3 [4.3]; $P<.001$ and 36.9 [9.1] vs 33.6 [7.8]; $P<.001$, respectively). Black children had higher TPA $(P=.001)$, as did children whose parents were less educated $(P=.04)$.

\section{Table 1 Characteristics of 865 and 746 Fifth-Grade Children}

\begin{tabular}{lccccc}
\hline & \multicolumn{2}{c}{$\begin{array}{c}\text { Total PA } \\
\text { sample = 865 }\end{array}$} & & \multicolumn{2}{c}{$\begin{array}{c}\text { Afterschool } \\
\text { PA sample = 746 }\end{array}$} \\
\cline { 2 - 3 } \cline { 6 - 6 } Characteristic & N & $\begin{array}{c}\text { \% or } \\
\text { mean (SD) }\end{array}$ & & N & $\begin{array}{c}\text { \% or } \\
\text { mean (SD) }\end{array}$ \\
\hline Males & 393 & 45.4 & & 338 & 45.3 \\
Race & & & & & \\
$\quad$ Black & 304 & 35.1 & & 265 & 35.5 \\
$\quad$ Hispanic & 90 & 10.4 & & 78 & 10.5 \\
$\quad$ Other & 149 & 17.2 & & 127 & 17.0 \\
$\quad$ White & 322 & 37.2 & & 276 & 37.0 \\
Parent education & 505 & 58.4 & & 439 & 58.6 \\
>high school & & & & & \\
Age, y & 865 & $10.6(0.5)$ & 746 & $10.6(0.5)$ \\
\hline
\end{tabular}

Abbreviation: PA, physical activity.

\section{Table 2 PA (in Minutes per Hour) by Youth Characteristics}

\begin{tabular}{llccc}
\hline Characteristic & $\begin{array}{c}\text { Total PA } \\
\mathbf{N}=\mathbf{8 6 5}\end{array}$ & $\begin{array}{c}\boldsymbol{P} \\
\text { value }\end{array}$ & $\begin{array}{c}\text { PA after } \\
\text { school } \\
\mathbf{N}=\mathbf{7 4 6}\end{array}$ & $\begin{array}{c}\boldsymbol{P} \\
\text { value }\end{array}$ \\
\hline Sex & & & & \\
$\quad$ Boys & $29.3(4.5)$ & $<.001$ & $36.9(9.1)$ & $<.001$ \\
$\quad$ Girls & $27.3(4.3)$ & & $33.6(7.8)$ & \\
Race & & & & \\
$\quad$ Black ${ }^{*}$ & $28.9(4.5)$ & .001 & $35.4(9.4)$ & .66 \\
Hispanic & $28.5(4.5)$ & & $35.8(8.2)$ & \\
Other & $27.4(4.9)$ & & $34.6(9.0)$ & \\
$\quad$ White & $27.8(4.2)$ & & $34.8(7.6)$ & \\
Parent education & & & & \\
$\quad$ High school & $28.6(4.4)$ & .04 & $35.7(9.2)$ & .11 \\
$\quad>$ High school & $27.9(4.5)$ & & $34.7(8.1)$ & \\
\hline
\end{tabular}

Abbreviation: PA, physical activity.

*Blacks are significantly higher than other and white. 


\section{Operationalizing a "Physical Activity Desert"}

As shown in Table 3, 12 variables were considered for operationalizing a physical activity desert based on the data available in this study. These included "no facilities" (no commercial facilities within a 2-mile buffer), "no parks" (no parks within a 0.75-mile buffer), "low play spaces" (no social spaces on windshield survey), "no cohesion" (lack of evidence of social cohesion on the windshield survey territoriality scale), "incivilities" (from the windshield survey incivilities scale), "no close resources" (no commercial facilities within 0.5 miles of the home address), "busy streets" (child lives on a major or minor thoroughfare), "resides in industrial zone" (any portion of a 0.75 -mile buffer around the home coded for industrial use), "lack of indoor school facilities" (lack of presence of indoor facilities at school), "lack of outdoor school facilities" (lack of presence of outdoor facilities at school), "no access to school facilities" (lack of open community access to school facilities outside school hours), and "lack of home equipment" (low number of physical activity equipment in and around the home).

After careful examination, "busy streets," "resides in industrial zone," "no close facilities," "lack of home equipment," and all 3 school environment variables (indoor and outdoor facilities and community access) were eliminated as potential components of the operational definition of "physical activity desert." The "busy streets" variable was assessed with items also used to assess the

\section{Table 3 List of Variables Considered for Operationalizing PA Desert}

\begin{tabular}{ll}
\hline $\begin{array}{l}\text { PA desert } \\
\text { variable }\end{array}$ & PA desert definition \\
\hline $\begin{array}{l}\text { No commercial } \\
\text { facilities }\end{array}$ & $\begin{array}{l}\text { No commercial PA facility within a } \\
\text { 2-mile buffer of the child's home addres }\end{array}$ \\
No parks & $\begin{array}{l}\text { No park within a 0.75-mile buffer of } \\
\text { child's home address }\end{array}$ \\
Low play spaces & $\begin{array}{l}\text { Absence of play space and social } \\
\text { interactions observed during windshield } \\
\text { survey of child's street segment }\end{array}$ \\
No cohesion & $\begin{array}{l}\text { Lack of evidence of neighborhood } \\
\text { cohesion/ownership/pride observed } \\
\text { during windshield survey of child's } \\
\text { street segment }\end{array}$
\end{tabular}

Incivilities

Presence of negative esthetic attributes observed during windshield survey of child's street segment

\section{No close} resources

Busy streets

Resides in industrial zone

Lack of school indoor facilities

Lack of school outdoor facilities Open community access to school facilities

Lack of home equipment

\section{Operationalization}

Count of commercial facilities in buffer

dichotomized as $0 / 1$; PA desert $=$ no facilities

Count of parks in buffer dichotomized as $0 / 1$; PA desert $=$ none

Observation of people outside, children playing, yards and porches, park on street, sidewalks, nonbusy street; 9-item score dichotomized as PA desert $=$ score of 2 or less

Observation of crime watch signs, borders/ hedges, watchful reactions by homeowners, decorations on homes, sign denoting neighborhood; 6-item score dichotomized as PA desert $=$ score of 0

Observation of vacant residences, poor grounds, litter, graffiti, poor condition of or vacant commercial buildings, poor condition of public spaces; 7-item score dichotomized with PA desert $=$ score of $1+$ Number (count) of PA facilities in 0.5-mile buffer of child's home address including any church, school, park, commercial facility

Child's street segment observed to be a major (4 lane) or minor (2 lane) thoroughfare with higher speed limits road; The proportion of the 0.75-mile buffer around a child's home inside the industrial zone; dichotomized with PA desert = any of the buffer was in an industrial zone

Number of indoor PA resources at school; 8 items

Number of outdoor PA resources at school; 9 items

Yes/no for 6 categories: child free play, child sports, child community programs, adult free use, adult sports, and adult community programs

Number of PA equipment items reported; 14 items

\begin{tabular}{ll}
$\begin{array}{l}\text { Data } \\
\text { source }\end{array}$ & Disposition \\
\hline $\begin{array}{l}\text { Counts of } \\
\text { resources }\end{array}$ & $\begin{array}{l}\text { Selected for PA } \\
\text { desert index }\end{array}$ \\
$\begin{array}{l}\text { Counts of } \\
\text { resources }\end{array}$ & $\begin{array}{l}\text { Selected for PA } \\
\text { desert index }\end{array}$ \\
$\begin{array}{l}\text { Windshield } \\
\text { (social }\end{array}$ & $\begin{array}{l}\text { Selected for PA } \\
\text { desert index } \\
\text { spaces) }\end{array}$ \\
\end{tabular}

Windshield

Selected for PA (territoriality) desert index

Windshield

Selected for PA (incivilities) desert index

Counts of

Not selected; resources redundant with no commercial facilities

Windshield Not selected; (busy street) limited variability

Land use and

Not selected; zoning codes industrial zone defined differently in different communities

PE teacher

Not selected; limited variability

PE teacher

Not selected; limited variability

School Not selected; administrator limited variability

Parent

Not selected; reflects home rather than built environment 
"low play spaces" variable from the windshield survey and showed limited variability, as few students lived on busy streets. Zoning and land use data sets used to define "resides in industrial zone" were not used because of inconsistent definitions for industrial areas between the 2 communities in the study. "No close resources" (ie, facilities within 0.5 miles of the home) was redundant with "no facilities" and "no parks." Home-based resources were excluded because it was decided that the features assessed in the home were not built environment features. There was little variability in community access to school facilities because policies in the 2 school districts participating in this study made them inconsistently available outside school hours.

The final list of variables to test for defining a physical activity desert included "no facilities" (ie, absence of a commercial facility within a 2-mile buffer of the child's home), "no parks" (ie, absence of a park within a 0.75 -mile buffer), "low play spaces" (ie, absence of inviting play and social spaces on the child's street segment), "no cohesion" (ie, absence of observed neighborhood cohesion on the child's street segment), and "incivilities" (ie, presence of negative esthetic attributes on the child's street segment). The definition, operationalization (coding), and data source for each physical activity desert variable are presented in Table 3 .

Table 4 presents univariate associations between each physical activity desert variable and child physical activity. Children with no parks within 0.75 miles of the home $(\mathrm{n}=770 ; 28.1 \mathrm{~min} / \mathrm{h} ; P=.03)$ had less TPA than children with parks present $(\mathrm{n}=95 ; 29.3 \mathrm{~min} / \mathrm{h})$. No other proposed physical activity desert variables were associated with physical activity.

\section{Comparing Physical Activity of Children Residing and Not Residing in Physical Activity Deserts}

Table 5 presents the results of stepwise regression models to examine combinations of all physical activity desert variables and associations with TPA and ASPA. "No parks" was the only physical activity desert variable that entered the models for TPA, and it entered consistently at $P=.01$ in all models (single variable model through 5-variable model). For ASPA, "no parks" entered all models with borderline significance, the 2-variable model at $P=.05$ and 3 - to 5 -variable models at $P=.06$ for each.

Table 6 presents a mixed model regression for physical activity and possible physical activity desert variables. After adjusting for gender, race/ethnicity, and parent education, "no parks" was the only PA desert variable negatively related to TPA $(P=.03)$. Similarly, "no parks" had a borderline negative $(P=.06)$ relationship with ASPA.

\section{Discussion}

This exploratory study applied a novel analytic strategy in operationally defining and testing the efficacy of the physical activity desert, conceptualized as "an area characterized by poor access to elements of the built environment that support or enable participation in physical activity." This study used data from a previous investigation that had measured both children's physical activity and a comprehensive set of physical environmental factors. Twelve variables were selected from the available data set as potential contributors to a multivariate operationalization of the physical activity desert. Seven of these were excluded upon initial examination due to redundancy with other candidate variables, lack of variability in this data set, and inconsistency in methods between the 2 communities in the study. The remaining 5 variables were adopted as an operational definition of a physical activity desert. The associations of these variables with children's physical activity were examined with both univariate and multivariate models. In the data available for this study, only having no park located within 0.75 miles of the child's home was associated with physical activity. The association between having no parks and all-day physical activity is statistically significant, whereas the association between having no parks and afterschool physical activity is not,

Table 4 Univariate Relationships Between TPA and ASPA and PA Desert Items

\begin{tabular}{|c|c|c|c|c|c|c|}
\hline \multirow[b]{2}{*}{ Desert items } & \multicolumn{3}{|c|}{$\begin{array}{l}\text { Total PA, min/h } \\
\qquad \mathrm{N}=865\end{array}$} & \multicolumn{3}{|c|}{$\begin{array}{c}\text { Total PA after 3:00 PM on weekdays } \\
\text { and all-day Sat, min/h } \\
\mathrm{N}=746\end{array}$} \\
\hline & $\mathbf{n}$ & Mean (SD) & $P$ value & $\mathbf{n}$ & Mean (SD) & $P$ value \\
\hline \multicolumn{7}{|l|}{ No facilities } \\
\hline Desert & 360 & $28.1(4.3)$ & .77 & 304 & $35.4(7.6)$ & .32 \\
\hline Not desert & 505 & $28.2(4.7)$ & & 442 & $34.8(9.1)$ & \\
\hline \multicolumn{7}{|l|}{ No parks } \\
\hline Desert & 770 & $28.1(4.4)$ & .03 & 658 & $34.9(7.9)$ & .23 \\
\hline Not desert & 95 & $29.3(5.2)$ & & 88 & $36.5(12.4)$ & \\
\hline \multicolumn{7}{|c|}{ Low play spaces } \\
\hline Desert & 221 & $28.1(4.5)$ & .75 & 190 & $35.3(9.4)$ & .75 \\
\hline Not desert & 644 & $28.2(4.5)$ & & 556 & $35.0(8.3)$ & \\
\hline \multicolumn{7}{|l|}{ No cohesion } \\
\hline Desert & 356 & $28.0(4.7)$ & .34 & 307 & $34.8(8.6)$ & .52 \\
\hline Not desert & 509 & $28.3(4.4)$ & & 439 & $35.2(8.6)$ & \\
\hline \multicolumn{7}{|l|}{ Incivilities } \\
\hline Desert & 227 & $28.0(4.7)$ & .46 & 189 & $35.2(10.2)$ & .81 \\
\hline Not desert & 638 & $28.3(4.5)$ & & 557 & $35.0(8.0)$ & \\
\hline
\end{tabular}

Abbreviations: PA, physical activity; TPA, total physical activity. Note: After deletions for missing race and parent education. 
Table 5 Stepwise Regression Analysis for TPA and ASPA and Desert Items, Using a .99 P Value for Level of Entry

\begin{tabular}{|c|c|c|c|c|c|c|c|c|}
\hline \multirow[b]{2}{*}{ Step } & \multicolumn{4}{|c|}{ Total PA, $n=865$} & \multicolumn{4}{|c|}{ Total PA after 3:00 PM and Sat, $n=746$} \\
\hline & Desert variable & $\beta$ (SE) & $F$ value & $P$ value & Variable & $\beta$ & $F$ value & $P$ value \\
\hline 1 & No parks & $-1.23(0.49)$ & 6.33 & .01 & No parks & $-1.62(0.97)$ & 2.78 & .10 \\
\hline \multirow[t]{2}{*}{2} & No parks & $-1.27(0.49)$ & 6.73 & .01 & No parks & $-1.92(0.99)$ & 3.71 & .05 \\
\hline & Incivilities & $-0.34(0.35)$ & 0.95 & .33 & No facilities & $0.89(0.65)$ & 1.86 & .17 \\
\hline \multirow[t]{3}{*}{3} & No parks & $-1.27(0.49)$ & 6.71 & .01 & No parks & $-1.90(1.00)$ & 3.63 & .06 \\
\hline & Incivilities & $-0.42(0.36)$ & 1.36 & .24 & No facilities & $0.87(0.65)$ & 1.79 & .18 \\
\hline & No cohesion & $-0.35(0.32)$ & 1.22 & .27 & No cohesion & $-0.34(0.64)$ & 0.28 & .60 \\
\hline \multirow[t]{4}{*}{4} & No parks & $-1.30(0.50)$ & 6.67 & .01 & No parks & $-1.90(1.00)$ & 3.63 & .06 \\
\hline & Incivilities & $-0.42(0.36)$ & 1.39 & .24 & No facilities & $0.88(0.65)$ & 1.82 & .18 \\
\hline & No cohesion & $-0.35(0.32)$ & 1.19 & .28 & Low play spaces & $0.26(0.72)$ & 0.13 & .72 \\
\hline & No facilities & $0.08(0.32)$ & 0.06 & .80 & No cohesion & $-0.33(0.64)$ & 0.26 & .61 \\
\hline \multirow[t]{5}{*}{5} & No parks & $-1.29(0.50)$ & 6.64 & .01 & No parks & $-1.90(1.00)$ & 3.61 & .06 \\
\hline & Incivilities & $-0.41(0.36)$ & 1.31 & .25 & No facilities & $0.88(0.66)$ & 1.82 & .18 \\
\hline & No cohesion & $-0.35(0.32)$ & 1.20 & .27 & Low play spaces & $0.27(0.73)$ & 0.13 & .72 \\
\hline & No facilities & $0.08(0.32)$ & 0.06 & .81 & No cohesion & $-0.34(0.65)$ & 0.27 & .61 \\
\hline & Low play spaces & $-0.07(0.35)$ & 0.04 & .83 & Incivilities & $-0.06(0.74)$ & 0.01 & .94 \\
\hline
\end{tabular}

Abbreviations: PA, physical activity; TPA, total physical activity.

Table 6 Linear Regression for TPA, ASPA, and Proposed PA Desert Variables

\begin{tabular}{|c|c|c|c|c|}
\hline \multirow[b]{2}{*}{ Variable } & \multicolumn{2}{|c|}{ Total PA $(n=865)$, adjusted ${ }^{a}$} & \multicolumn{2}{|c|}{$\begin{array}{l}\text { PA after 3:00 PM and Sat } \\
\quad(n=746), \text { adjusted }^{\mathrm{a}}\end{array}$} \\
\hline & $\beta$ (SE) & $P$ value & $\beta$ (SE) & $P$ value \\
\hline No facilities & $0.11(0.31)$ & .72 & $0.88(0.64)$ & .17 \\
\hline No parks & $-1.05(0.49)$ & .03 & $-1.85(0.99)$ & .06 \\
\hline Low play spaces & $-0.18(0.34)$ & 61 & $0.13(0.72)$ & .86 \\
\hline No cohesion & $-0.13(0.31)$ & 69 & $-0.12(0.64)$ & .85 \\
\hline Incivilities & $-0.70(0.36)$ & .05 & $-0.36(0.75)$ & .63 \\
\hline
\end{tabular}

Abbreviations: PA, physical activity; TPA, total physical activity.

${ }^{a}$ Adjusted for gender, race, and parent education.

likely due to lower statistical power linked to the smaller sample size for afterschool physical activity. It is also likely that park proximity influences children's physical activity in ways that go beyond literal access during nonschool hours.

The association between the availability of parks nearby and increased physical activity is well supported by the literature. ${ }^{27,35} \mathrm{~A}$ recent review found that providing quality parks and playgrounds was associated with physical activity and visitation in all ages. ${ }^{36}$ Park availability is often included in a broader category of the availability of recreational/physical activity facilities, which often results in conflicting findings. ${ }^{37,38}$ Our study suggests that different aspects of the built environment may have differential influences; thus, examining specific features separately may help elucidate these relationships. Given the overall evidence for an association between park availability and physical activity, there have been calls to improve both the quality and availability of parks. Most notably, the Trust for Public Land is leading a US initiative to have safe convenient access to a park within a 10-minute walk of every home. ${ }^{39}$

Unlike the term "food desert," which has received significant scientific investigation and media attention, ${ }^{15,40}$ there are few references to physical activity deserts. Physical activity deserts were briefly described in a book on population health, ${ }^{31,41}$ Timperio et $\mathrm{al}^{42}$ used the term "playability" to reference built and social environmental features supportive of physical activity, and the term "play desert" was used to describe underutilized parks in Pittsburgh. ${ }^{31}$ Using terms that are more accessible and understandable by the public, like physical activity desert, can help the public better understand scientific research and allow people to make more informed decisions. ${ }^{43}$

This study, to the best of the authors' knowledge, is the first to test the significance of an operational definition of "physical activity desert." Accordingly, it is readily acknowledged that the work presented here is limited by the specific conceptual and analytic approaches that were applied. The authors proposed a specific conceptual definition of physical activity desert and then, based on consideration of previous research findings, selected constructs that were consistent with that definition. Statistical analyses including both bivariate and multivariate procedures were used to examine associations between measures of the selected constructs and objectively measured physical activity. It is acknowledged that the study design adopted by the authors is only one of several approaches that could be applied in addressing the aims of this study. It is recommended that other approaches be 
applied in future studies. In addition, the study was limited by the nature of the data set within which the analyses were performed, including limited variability in some variables. Analyses were performed in a sample of 10- to 11-year-old children residing in the southeastern United States, and all were attending elementary schools in 2 public school districts. The demographic composition of this sample is a significant limitation of the study, and it is readily acknowledged that analytic procedures like those applied in this study could yield different findings if applied to samples of different ages, different sociocultural characteristics, and different geographic locations. Furthermore, environmental support for active transport to school is a potentially important construct. We did not have the information needed to produce a rating of this construct, which is a limitation of the study. Nonetheless, this study contributes preliminary conceptual and operational definitions of "physical activity desert." It is recommended that future studies of physical activity deserts be undertaken in larger and more diverse samples.

The strengths of this study include the systematic methodology used to conceptualize and operationalize a "physical activity desert." Specifically, we began with a comprehensive set of variables and systematically examined each of them for suitability rather than focusing on a specific variable, such as parks, from the outset. Furthermore, we focused on the associations between a physical activity desert and physical activity behavior in children; much of the "food desert" literature focuses on broader outcomes, such as obesity. Finally, we used an objective measure of physical activity in all analyses.

\section{Conclusion}

This exploratory study adopted a conceptual definition of the physical activity desert and conducted a series of analyses aimed at operationalizing that definition. The operational definition included 5 elements of the built environment. Multivariate analyses demonstrated that, in the data available in this study, only the variable reflective of the proximity of a child's home to a park was associated with children's physical activity, measured by accelerometry. Children living in a "no park" zone were less active than children living close to a park. Future studies should continue to evaluate operational definitions of physical activity deserts in additional data sets based in different geographic areas.

\section{Acknowledgments}

The authors thank Gaye Groover Christmus, MPH, for providing technical and editorial assistance in the development of the manuscript. The study was funded by a grant from the National Heart, Lung, and Blood Institute (R01HL091002). A.B. was funded in part by a grant from the National Institute of General Medical Sciences (T32GM081740). The authors have no conflicts of interest to report.

\section{References}

1. N. C. D. Risk Factor Collaboration. Worldwide trends in bodymass index, underweight, overweight, and obesity from 1975 to 2016: a pooled analysis of 2416 population-based measurement studies in 128.9 million children, adolescents, and adults. Lancet. 2017; 390(10113):2627-2642. doi:10.1016/S0140-6736(17)32129-3

2. Skinner AC, Perrin EM, Skelton JA. Prevalence of obesity and severe obesity in US children, 1999-2014. Obesity. 2016;24(5):1116-1123. PubMed ID: 27112068 doi:10.1002/oby.21497
3. Heerman WJ, Krishnaswami S, Barkin SL, McPheeters M. Adverse family experiences during childhood and adolescent obesity. Obesity. 2016;24(3):696-702. PubMed ID: 26853526 doi:10.1002/oby.21413

4. Waters E, de Silva-Sanigorski A, Hall BJ, et al. Interventions for preventing obesity in children. Cochrane Database Syst Rev. 2011; 12:CD001871. PubMed ID: 22161367 doi:10.1002/14651858. cd001871.pub3

5. Fang D, Thomsen MR, Nayga RM Jr, Goudie A. Association of neighborhood geographic spatial factors with rates of childhood obesity. JAMA Netw Open. 2018;1(4):e180954. PubMed ID: 30646092 doi: 10.1001/jamanetworkopen.2018.0954

6. Hughey SM. Exploring spatial patterning and the impact of obesogenic built environments for youth obesity (doctoral dissertation). 2017. https://scholarcommons.sc.edu/etd/4192/. Accessed February 17, 2020.

7. Nau C, Schwartz BS, Bandeen-Roche K, et al. Community socioeconomic deprivation and obesity trajectories in children using electronic health records. Obesity. 2015;23(1):207-212. PubMed ID: 25324223 doi:10.1002/oby.20903

8. Alvarado SE. Neighborhood disadvantage and obesity across childhood and adolescence: evidence from the NLSY children and young adults cohort (1986-2010). Soc Sci Res. 2016;57:80-98. PubMed ID: 26973033 doi:10.1016/j.ssresearch.2016.01.008

9. Greves Grow HM, Cook AJ, Arterburn DE, Saelens BE, Drewnowski A, Lozano P. Child obesity associated with social disadvantage of children's neighborhoods. Soc Sci Med. 2010;71(3):584-591. PubMed ID: 20541306 doi:10.1016/j.socscimed.2010.04.018

10. Watson KB, Harris CD, Carlson SA, Dorn JM, Fulton JE. Disparities in adolescents' residence in neighborhoods supportive of physical activity-United States, 2011-2012. MMWR Morb Mortal Wkly Rep. 2016;65(23):598-601. PubMed ID: 27309671 doi:10.15585/mmwr. mm6523a2

11. Larson NI, Story MT, Nelson MC. Neighborhood environments: disparities in access to healthy foods in the U.S. Am J Prev Med. 2009; 36(1):74-81. PubMed ID: 18977112 doi:10.1016/j.amepre.2008. 09.025

12. Must A, Tybor DJ. Physical activity and sedentary behavior: a review of longitudinal studies of weight and adiposity in youth. Int $J$ Obes. 2005;29(suppl 2):S84-S96. PubMed ID: 16385758 doi:10.1038/sj. ijo.0803064

13. Fulton JE, Dai S, Steffen LM, Grunbaum JA, Shah SM, Labarthe DR. Physical activity, energy intake, sedentary behavior, and adiposity in youth. Am J Prev Med. 2009;37(1):S40-S49. PubMed ID: 19524155 doi:10.1016/j.amepre.2009.04.010

14. Wang Y, Beydoun MA. The obesity epidemic in the United Statesgender, age, socioeconomic, racial/ethnic, and geographic characteristics: a systematic review and meta-regression analysis. Epidemiol Rev. 2007;29(1):6-28. PubMed ID: 17510091 doi:10.1093/epirev/ $\mathrm{mxm} 007$

15. Beaulac J, Kristjansson E, Cummins S. A systematic review of food deserts, 1966-2007. Prev Chronic Dis. 2009;6(3):A105. PubMed ID: 19527577

16. Caspi CE, Sorensen G, Subramanian SV, Kawachi I. The local food environment and diet: a systematic review. Health Place. 2012;18(5): 1172-1187. PubMed ID: 22717379 doi:10.1016/j.healthplace.2012. 05.006

17. Dutko P, Ver Ploeg M, Farrigan T. Characteristic and Influential Factors of Food Deserts. Washington, DC: US Department of Agriculture, Economic Research Service; 2012.

18. Cobb LK, Appel LJ, Franco M, Jones-Smith JC, Nur A, Anderson CA. The relationship of the local food environment with obesity: a systematic review of methods, study quality, and results. Obesity. 
2015;23(7):1331-1344. PubMed ID: 26096983 doi:10.1002/oby. 21118

19. Gamba RJ, Schuchter J, Rutt C, Seto EY. Measuring the food environment and its effects on obesity in the United States: a systematic review of methods and results. J Community Health. 2015; 40(3):464-475. PubMed ID: 25326425 doi:10.1007/s10900-0149958-z

20. Cummins S, Flint E, Matthews SA. New neighborhood grocery store increased awareness of food access but did not alter dietary habits or obesity. Health Aff. 2014;33(2):283-291. PubMed ID: 24493772 doi: 10.1377/hlthaff.2013.0512

21. Shier V, Nicosia N, Datar A. Neighborhood and home food environment and children's diet and obesity: evidence from military personnel's installation assignment. Soc Sci Med. 2016;158:122-131. PubMed ID: 27135542 doi:10.1016/j.socscimed.2016.03.043

22. Gustafson A, Lewis S, Perkins S, Wilson C, Buckner E, Vail A. Neighbourhood and consumer food environment is associated with dietary intake among Supplemental Nutrition Assistance Program (SNAP) participants in Fayette County, Kentucky. Public Health Nutr. 2013;16(7):1229-1237. PubMed ID: 23462377 doi:10.1017/ S1368980013000505

23. An R, Sturm R. School and residential neighborhood food environment and diet among California youth. Am J Prev Med. 2012;42(2): 129-135. PubMed ID: 22261208 doi:10.1016/j.amepre.2011.10.012

24. Jimenez-Pavon D, Kelly J, Reilly JJ. Associations between objectively measured habitual physical activity and adiposity in children and adolescents: systematic review. IntJ PediatrObes. 2010;5(1): 3-18. PubMed ID: 19562608 doi:10.3109/17477160903067601

25. Rey-Lopez JP, Vicente-Rodriguez G, Biosca M, Moreno LA. Sedentary behaviour and obesity development in children and adolescents. NutrMetab Cardiovasc Dis. 2008;18(3):242-251. PubMed ID: 18083016 doi:10.1016/j.numecd.2007.07.008

26. Ding D, Sallis JF, Kerr J, Lee S, Rosenberg DE. Neighborhood environment and physical activity among youth: a review. Am J Prev Med. 2011;41(4):442-455. PubMed ID: 21961474 doi:10.1016/j. amepre.2011.06.036

27. Davison KK, Lawson CT. Do attributes in the physical environment influence children's physical activity? A review of the literature. Int $J$ Behav Nutr Phys Act. 2006;3(1):19. PubMed ID: 16872543 doi:10. 1186/1479-5868-3-19

28. McGrath LJ, Hopkins WG, Hinckson EA. Associations of objectively measured built-environment attributes with youth moderate-vigorous physical activity: a systematic review and meta-analysis. Sports Med. 2015;45(6):841-865. PubMed ID: 25618013 doi:10.1007/s40279015-0301-3

29. Colabianchi N, Clennin MN, Dowda M, et al. Moderating effect of the neighbourhood physical activity environment on the relation between psychosocial factors and physical activity in children: a longitudinal study. J Epidemiol Community Health. 2019;73(7): 598-604. PubMed ID: 30967488 doi:10.1136/jech-2018-211456

30. Brownson RC, Hoehner CM, Day K, Forsyth A, Sallis JF. Measuring the built environment for physical activity: state of the science. Am J
Prev Med. 2009;36(4)(suppl):S99-S123.e12. PubMed ID: 19285216 doi:10.1016/j.amepre.2009.01.005

31. Cohen DA, Hunter G, Williamson S, Dubowitz T. Are food deserts also play deserts? J Urban Health. 2016;93(2):235-243. PubMed ID: 27033184 doi:10.1007/s11524-015-0024-7

32. Pate RR, Dowda M, Dishman RK, Colabianchi N, Saunders RP, McIver KL. Change in children's physical activity: predictors in the transition from elementary to middle school. Am J Prev Med. 2019; 56(3):e65-e73. PubMed ID: 30655084 doi:10.1016/j.amepre.2018. 10.012

33. Evenson KR, Sotres-Alvarez D, Herring AH, Messer L, Laraia BA, Rodriguez DA. Assessing urban and rural neighborhood characteristics using audit and GIS data: derivation and reliability of constructs. Int J Behav Nutr Phys Act. 2009;6(1):44. PubMed ID: 19619325 doi: 10.1186/1479-5868-6-44

34. Lee SM, Burgeson CR, Fulton JE, Spain CG. Physical education and physical activity: results from the School Health Policies and Programs Study 2006. J Sch Health. 2007;77(8):435-463. PubMed ID: 17908102 doi:10.1111/j.1746-1561.2007.00229.x

35. Slater S, Colabianchi N. What influences park use and physical activity? Transl Behav Med. 2014;4(2):130. PubMed ID: 24904695 doi:10.1007/s13142-014-0255-2

36. Smith M, Hosking J, Woodward A, et al. Systematic literature review of built environment effects on physical activity and active transport - an update and new findings on health equity. Int J Behav Nutr Phys Act. 2017;14(1):158. PubMed ID: 29145884 doi:10.1186/ s12966-017-0613-9

37. Ferreira I, van der Horst K, Wendel-Vos W, Kremes S, van Lenthe FJ, Brug J. Environmental correlates of physical activity in youth-a review and update. Obes Rev. 2006;8(2):129-154. PubMed ID: 17300279 doi:10.1111/j.1467-789X.2006.00264.x

38. Van Der Horst K, Paw MJ, Twisk JW, Van Mechelen W. A brief review on correlates of physical activity and sedentariness in youth. Med Sci Sports Exerc. 2007;39(8):1241-1250. PubMed ID: 17762356 doi:10.1249/mss.0b013e318059bf35

39. The Trust for Public Land. https://www.tpl.org/10minutewalk. Published 2018. Accessed May 14, 2020.

40. Walker RE, Keane CR, Burke JG. Disparities and access to healthy food in the United States: a review of food deserts literature. Health Place. 2010;16(5):876-884. PubMed ID: 20462784 doi:10.1016/j. healthplace.2010.04.013

41. Mayzell G. Population Health: An Implementation Guide to Improve Outcomes and Lower Costs. New York, NY: Productivity Press; 2015.

42. Timperio A, Reid J, Veitch J. Playability: built and social environment features that promote physical activity within children. Curr Obes Rep. 2015;4(4):460-476. PubMed ID: 26399255 doi:10.1007/ s13679-015-0178-3

43. Brownell SE, Price JV, Steinman L. Science communication to the general public: why we need to teach undergraduate and graduate students this skill as part of their formal scientific training. J Undergrad Neurosci Educ. 2013;12(1):E6-E10. PubMed ID: 24319399 